\title{
Comprehension and Idiom Learning of Iranian EFL Learners
}

\section{Omid Tabatabaei}

\author{
English Department, Najafabad Branch, Islamic Azad University, Najafabad, Iran
}

\author{
Masoud Mirzaei \\ Shahreza Branch, Islamic Azad University, Iran \\ E-mail: emmirzaei@yahoo.com
}

\section{Doi:10.5901/jesr.2014.v4n1p45}

\section{Abstract}

\begin{abstract}
This study investigated the effects of different types of multimedia glosses, namely text, picture, and text plus picture on online computerized L2 text comprehension and idiom learning of English university students. From a population of 141 volunteers based on their performance on a Standard English proficiency text (Nelson), 60 female university students were selected. Then, they were randomly assigned to 4 groups of 15, three gloss groups, subsequently exposed to the research treatment and one control group. Taking advantage of the results of the pilot study, some idioms of the computerized written texts were glossed and hyperlinked by a computer software program. When the students clicked on hyperlinked idioms, a new page appeared and showed the idiom with a definition in English (textual gloss group), a picture (pictorial gloss group), or a combination of both definition and picture (textual plus pictorial gloss group ). Participant in each experimental group read the text under one of the three mentioned conditions. Statistical analyses of the results reveal that 1) all multimedia gloss groups comprehended computerized L2 texts significantly better than the control group, 2). A significant difference between the multimedia gloss groups and the control group in the production of the target idiom items was found. 3)The mix gloss group insignificantly outperformed the textual and pictorial gloss groups in computerized L2 text comprehension, and 4) regarding idiom learning, the findings of this study indicate that utilizing computers and multimedia glosses can be influential in language teaching in general and online L2 text comprehension as well as idiom learning in particular.
\end{abstract}

Keywords: L2 text comprehension, online computerized text, gloss, multimedia gloss, idiom learning.

\section{Introduction}

The ability to learn language is among the greatest mental achievements of mankind (Hudson, 1980). In spite of the vast amount of research by scholars on different, but related fields, they have not provided sufficient evidence concerning the nature of the procedures that this achievement relies on. Only in recent years have linguists and educators in various language- related fields been able to understand, to some extent, what language is and how it is learned as a second or foreign language and how it can be taught.

Many teachers believe that different teaching methods play important roles in the quality of learning, especially learning a second or foreign language. Language is composed of many different components each of which is important in learning language. Idioms and metaphoric expressions are important parts of Learning and understanding the second or foreign language. Gibbs (1992) believed that EFL learners can further comprehend texts that contain metaphorical and lexical meanings beyond the basic word level by developing a clear understanding of figurative language and idioms. But what is an idiom? And how can it be defined?

\section{Literature Review}

In every language one area that causes problem is idioms. But what exactly are idioms? Idioms are a part of what Moon (1992, p. 13) calls:" fixed expressions" which are arguably "the most difficult part of the vocabulary of a language for learners to acquire fully" (Moon, 1992, p.25), however providing an exact definition of idiom is difficult.

In an attempt to define this term a look at Moon's (1992, p.14) divisions of "fixed expression" into three categories is necessary. The first category is "anomalous collocation" made up of combinations which are "different" either the from is grammatically ill (e.g., "through thick and thin" the adjectives "thick" and "thin" are used as nouns or in "at large" we 
have a collocation made up of a preposition and an adjective or one part of the collocation is fossilized within the collocation and never found outside (e.g. the word "after" in "from after" will never be used outside of this collocation (Moon, 1992). The second category is: proverbs, slangs, quotations, catchphrases, gambits, and closed-set turns: institutionalized or conventionalized stretches of language which are almost always stored and produced holistically and can be decoded compositionally, word by word, but may be considered idiomatic because of a mismatch between their compositional values and their overall pragmatic function (Moon, 1992, p.14).

An example of this is "half a loaf is better than none" (Moon, 1992). This proverb is stored as a unit and can easily understood by knowing the literal meanings of all the words which are used idiomatically.

The third category is the "pure idiom" which Moon (1992) has named it frozen or fossilized metaphor. Interestingly, it is not the case that idioms are frozen or dead metaphors. Some of these metaphors are considered retrievable. An example "skate on thin ice"; one can understand that skating on thin ice is dangerous. So, this idiom means to be in a dangerous situation. Others are opaque because one cannot deduce that spilling the beans, for example, means revealing a secret. To understand and define idioms, we must first define multi-word-unit and then word combination.

Idiomatic expressions or idioms are a particularly interesting variant of Fes, because their meaning is partly or completely non- compositional.

\subsection{Glossing}

All kinds of explanatory comment added to a text to clarify its meaning to the reader are called glossing. The most common types of glosses are: textual, pictorial, and a combination of the two. A more detailed discussion of glossing will be presented in the review of literature section (see chapter 2), but the important questions are why glossing is useful, and what its advantages are. The following explanation may serve as a simple answer to these questions.

Koren (1999) introduces glossing as the easiest way to understand the meanings of words as they appear in a context since it does not even demand the effort of searching and then choosing the appropriate meaning out of several possible ones, which is demanded by dictionary look- up.

A more complex form of glossing is 'multimedia'. According to Al-Seghayer (2001), multimedia is the use of text, graphics, animation, picture, video, and sound to present information.

\subsubsection{CALL Glosses}

The value of hypertext glosses was established in an early study by Aust, Kelley, and Roby (1993) that compared the use of conventional paper and hypertext dictionaries on reading comprehension. Participants were 80 undergraduate Spanish learners who were assigned to four conditions: condition 1 (English translation paper dictionary), condition 2 (simplified Spanish paper dictionary), condition3 (English hypertext dictionary), condition 4 (simplified Spanish hypertext dictionary). All words in the 420-word reading passage were glossed with pop-up definitions in hypertext. The frequency of consulting glosses, study time, efficiency (consultations per minute) and reading comprehension were considered using tracking software to monitor students' use of glosses and a recall protocol to measure reading comprehension. Results revealed higher efficiency of hypertext glosses as students in the hypertext conditions ( 3 and 4 ) consulted more than twice as many definitions and read the passage in less time with no comprehension loss.

Chun and Plass (1996) investigated the effect of multimedia annotations on the incidental vocabulary learning of 160 university German students. Using their computerized reading program, they conducted three studies, employing a within subjects design. The students used the same version of the program and worked with the program in a realistic L2 learning situation. Afterwards, the participants were tested on their incidental vocabulary learning and overall reading comprehension while being free to choose the available annotations. The results indicated that "the recall protocol for visual annotations (that is, words annotated with text and pictures, text and video) was higher than for words annotated with text alone" (p. 189).

\subsubsection{Non-CALL Glosses}

Davis (1989) found the value of conventional paper glosses on reading comprehension in a study with 71 French language learners in an American university. He used a 936 word story with 38 glosses in the text margin. Students were in one of three conditions: condition 1 (no gloss) read the story, wrote what they remembered and reread story; condition 2 (prior gloss) studied vocabulary, read story, wrote what they remembered and reread the text; gloss condition 3 
(embedded gloss) read the story with vocabulary definitions embedded as glosses, wrote what they remembered and reread the story. All three groups wrote what they remembered for 15 minutes. Results found that students in condition 2 (prior gloss) and condition 3 (embedded gloss) recalled significantly more information than students in condition 1 (no gloss).

The major problem and the main concern of this study is that checking the unknown idioms in a dictionary is really difficult. In the case of guessing or inferencing, it is also possible for the reader to make erroneous inferences for similar lexical forms or idioms. In fact, the problem arises from the point that even though there are several ways for presenting and introducing new idioms in a reading comprehension text, multimedia glossing (textual and/or pictorial) has not been appreciated, at least, in teaching reading and idioms at Iranian universities.

Some researchers report that students who are able to consult glosses before or during the reading process recalled more of the text than those without glossing aids (Davis, 1989; Jacobs, DuFon, \& Hong, 1994). However, this study tries to investigate the effects of different types of gloss (text, picture, and text+ picture) on computerized L2 text comprehension and idiom learning in order to have an empirical evidence of such an effect.

According to the stated problem, the following research questions have been addressed in this study:

1. Does exposure to any type of gloss (text, picture, and text plus picture) have a significant effect on L2 reader's comprehension of an online computerized reading text, as measured by a comprehension test?

2. Does exposure to any type of gloss (textual, pictorial, and textual plus pictorial) have a significant effect on L2 reader's learning of online computerized idiom, as measured by a production test?

3. Which type of gloss (text, picture, and text plus picture) has a more significant effect on L2 reader's comprehension of an online computerized reading text, as measured by a comprehension test?

4. Which type of gloss (textual, pictorial, and textual plus pictorial) has a more significant effect on L2 readers' learning of online computerized target idiom, as measured by a production test?

Based on the questions cited above, this study aimed at testing the following null hypotheses:

H1. Exposure to any type of gloss (text, picture, and text plus picture) does not have a significant effect on L2 readers' comprehension of an online computerized reading text, as measured by a comprehension test.

H2. Exposure to any type of gloss (textual, pictorial, and textual plus pictorial) does not have a significant effect on $\mathrm{L} 2$ readers' learning of online computerized idioms, as measured by a production test.

H3. None of the gloss types (text, picture, and text plus picture) have a more significant effect on L2 readers' comprehension of an online computerized reading text, as measured by a comprehension test.

H4. None of the gloss types (textual, pictorial, and textual plus pictorial) have a more significant effect on L2 readers' learning of online computerized idioms, as measured by a production test.

\section{Research Methodology}

\subsection{Participants}

A population of 141 female university students at Najafabad University participated at the time of the study. To assess their general language proficiency level, the standard proficiency test (Nelson, 2001) was administered. The Nelson test is a commercially developed package which is claimed to grade and place students reliably into appropriate levels. It was divided into two sections, reading comprehension and vocabulary consisted of 30 questions, which took about fifty five minutes for the participants to complete. (See Appendix A)

The students' performance on the Nelson test was analyzed to ensure that they were homogenous in terms of their proficiency level. Only the participants whose scores on this test fell between one standard deviation above and one standard deviation below the mean were selected. In other words, only $42.5 \%$ of the participants were qualified to be included in the study i.e., 60 out of 141 participants.

\subsection{Instrument}

In order to determine the general proficiency level of the participants and to screen them, reading and vocabulary sections of Nelson test (2001), including 30 questions, were administered as a criterion to determine the examinee's level of proficiency. The individual scores on these two sections of Nelson were analyzed to ensure that they were of the same level of language proficiency. (See appendix A)

A list of idioms from Pocket English Idioms written by Sullivan (2007) was tried out by the selected individuals in 
the pilot study in order to underline all the unknown idioms. Only idioms underlined by more than half of the participants were selected to be glossed. Then, three appropriate passages were taken from internet. They have been reviewed by experts in language teaching and testing. It was also necessary to determine the readability of the three computerized reading passages the participants were to receive on the day of exposure to the research treatment. The readability level of each computerized reading passage was computed separately by Microsoft Office Word 2007. The results were 77.5, 88.4 , and 78.8 respectively to match the readability of the passages to the students' proficiency levels. Based on the result of the pilot study, the passages were computerized, and some idioms of that computerized written passages were glossed, and hyperlinked by a computer software program called Power Point. The software included different slides that showed computerized reading passages with bold, and underlined idioms, the definition of the idiom, their pictures, and combinations of them (See Appendix B).

The participants were given three printed paper reading passages taken from internet which have been reviewed by experts in language teaching and testing, and also the readability of three passages was computed by Microsoft Office Word 2007 and the results were 75, 84.3, and 75.1 respectively.

All groups were given an achievement comprehension test including multiple-choice comprehension questions in English, after completing the production test (see Appendix $\mathrm{C}$ ). The reliability and validity of the comprehension tests were established. Some experts in language teaching and testing were asked to review the test, and there was a general agreement among them concerning the content validity of the test. The reliability of the test estimated by KR-21 formula was 0.82 .

\subsection{Procedure}

Participants in the three gloss groups received instructions for each gloss conditions on the day of exposure to the research treatment. All groups received the texts via internet since the computerized texts were added to university computer site for online teaching of reading and idiom. Participants worked through the text at their own pace and they were tested individually. This way of teaching was an online process. Textual gloss group read the online computerized written passages having access to the definitions of the glossed idioms in English. Pictorial gloss group read the online computerized written passages with access to the pictures. Textual plus pictorial gloss group read the online computerized written passages with access to the pictures and the definitions of the glossed idioms. Control group read the online computerized written texts without having any access to the definitions or pictures of the glossed idioms.

During the sessions of instruction, the participants had access to online reading passages at university computer site. As it was mentioned earlier, the participants in each group worked through the passages under different conditions. The gloss groups could consult glosses by placing the mouse pointer over the colored boldface idioms. When the participants clicked on the hyperlinked idioms, a new page appeared and showed the idiom with a definition in English (textual gloss group), a picture (pictorial gloss group), or a combination of both (textual plus pictorial gloss group).

Control group read the online computerized written texts without having any access to glosses. After completion of the online reading task in different conditions, the teacher-researcher asked participants some questions orally in order to assess whether any of them comprehended the passages and learned the glossed idioms.

In the next session which was held after four days, three printed paper reading passages followed by the production and comprehension tests were administered to the participants. These three printed paper reading passages are different from the three main online computerized passages of the experiment. But, they included the same idioms that were glossed in the experimental passages and with the same appropriate readability level. Participants read the printed paper passages one by one. After reading each passage, they took a paper version of the production and comprehension tests including 6 questions in the same session. Every passage included 3 production questions, and 3 multiple-choice comprehension questions. The 9 annotated idioms in the three experimental computerized reading passages were the focus of production tasks. Each computerized passage included 3 annotated idioms, so each printed paper passage was followed by 3 questions.

Participants performed the production tests first so that the multiple choice comprehension tests would not provide additional exposure to the target idioms, enhancing their recall. The annotated idiom in the reading texts were the focus of the production tests. Participants were given sentences in English and they were asked to complete. They could refer back to the texts to help them find an appropriate idiom for each question.

Comprehension tests include multiple-choice comprehension questions in English. Participants were permitted to consult with the texts to help them answer the comprehension questions if they needed to. The multiple-choice comprehension questions dealing with overall comprehension of the texts by considering specific meaning of the idioms 
glossed in the experimental texts, aimed at measuring whether participants achieved a clear understanding of events happening in the texts. The participants answered the questions on the answer sheets which were distributed towards the end of the reading task.

\section{Findings and Discussion}

The raw scores of the 60 participants were compiled for data analyses. The means and standard deviations of the obtained scores on the production and comprehension tests were calculated. A series of matched t-test were performed on the means of the two tests. One-way ANOVA was applied to compare the means of the groups on reading comprehension and idiom learning.

Table 4.1. One Sample t-Test Results of the Comprehension Test: Control and Text Gloss Groups

\begin{tabular}{|l|c|c|c|c|c|c|}
\hline & \multicolumn{9}{|c|}{ Test Value = 0} \\
\cline { 5 - 7 } & & \multirow{2}{*}{ Df } & Sig. (2-tailed) & $\begin{array}{c}\text { Mean } \\
\text { Difference }\end{array}$ & \multicolumn{2}{|c|}{$\begin{array}{c}\text { 95\% Confidence Interval of } \\
\text { the Difference }\end{array}$} \\
\cline { 6 - 8 } & & & & & Lower & Upper \\
\hline Textual gloss & 12.698 & 14 & .000 & 5.8655 & 5.700 & 8.036 \\
Control & 18.825 & 14 & .000 & 5.0000 & 5.340 & 6.663 \\
\hline
\end{tabular}

As table 4.1. indicates, the mean of the textual gloss group is 5.86 and the mean of the control group is 5.0. The difference between the means of the textual gloss group and control group represents that the participants in textual gloss group outperformed the control group on reading comprehension measures. A matched t-test was given to see if the difference is significant. The first null hypothesis is rejected because the observed $t$ is greater than the critical $t$ with 14 degree of freedom at the 0.05 level of significance. The level of significance is statistically significant.

Table 4.2. One Sample t-Test Results of comprehension Test: Control and Picture Gloss Groups

\begin{tabular}{|l|c|c|c|c|c|c|}
\hline & \multicolumn{3}{|c|}{ Test Value = 0 } \\
\cline { 5 - 7 } & & \multirow{2}{*}{ T } & \multirow{2}{*}{ Sig. (2-tailed) } & $\begin{array}{c}\text { Mean } \\
\text { Difference }\end{array}$ & \multicolumn{2}{|c|}{$\begin{array}{c}\text { 95\% Confidence Interval of the } \\
\text { Difference }\end{array}$} \\
\cline { 6 - 7 } & & & & & Lower & Upper \\
\hline Textual gloss & 14.442 & 14 & .000 & 5.9000 & 5.878 & 7.920 \\
Control & 18.825 & 14 & .000 & 5.0000 & 5.340 & 6.663 \\
\hline
\end{tabular}

Table 4.2. shows that the difference between the means of the pictorial gloss group and the control group and indicates that the participants in pictorial gloss group outperformed those of the control group on the reading comprehension test. A matched t-test was run to see if the difference is significant. The first null hypothesis is rejected because the significance level (.000) is smaller than the alpha level (0.05), and the difference between the means of two groups is meaningful. Therefore, exposure to picture gloss has a significant effect on $L 2$ readers' comprehension of an online computerized reading text.

Table 4.3. One Sample t-Test Results of the comprehension Test: Control and Text plus Picture Gloss Groups

\begin{tabular}{|l|c|c|c|c|c|c|}
\hline & \multicolumn{5}{|c|}{ Test Value = 0 } \\
\cline { 2 - 6 } & \multirow{2}{*}{$\mathrm{t}$} & $\mathrm{df}$ & Sig. (2-tailed) & $\begin{array}{c}\text { Mean } \\
\text { Difference }\end{array}$ & $\begin{array}{c}\text { 95\% Confidence Interval of } \\
\text { the Difference }\end{array}$ \\
\cline { 5 - 7 } & & & & & Lower & Upper \\
\hline Textual- pictorial & 13.190 & 14 & .000 & 6.5000 & 5.443 & 7.557 \\
control & 17.822 & 14 & .000 & 5.5000 & 4.838 & 6.162 \\
\hline
\end{tabular}

According to Table 4.3. it can be concluded that the amount of t-observed is significant at the probability level of $p=.000$, which is smaller than 0.05 . As this table shows, the mix gloss group significantly outperformed the control group on reading comprehension measures. The first null hypothesis is rejected, since the significance level (.000) is smaller than the alpha level (0.05). It can be concluded that multimedia annotations have a beneficial effect on comprehension of $L 2$ 
texts.

\subsection{Production Test Results of Three Gloss Group and Control Group}

To support or reject the second null hypothesis (i.e., Exposure to any type of gloss, text, picture, text plus picture does not have a significant effect on L2 readers' learning of online computerized target words as measured through a production test.), first the descriptive statistics of the participants' performance on the production test of both 'gloss group' (text, picture, and text plus picture) and 'control group' were calculated. Second, in order to compare the mean of each gloss group with that of control group on the production test, and to find out whether or not there is a meaningful difference between their means, a t-test was run.

Table 4.4. One Sample t-Test Results of the Production Test: Control and Text Gloss Groups

\begin{tabular}{|l|c|c|c|c|c|c|}
\hline \multirow{2}{*}{} & \multicolumn{6}{|c|}{ Test Value $=0$} \\
\cline { 5 - 7 } & \multirow{2}{*}{$\mathrm{t}$} & $\mathrm{df}$ & \multirow{2}{*}{ Sig. (2-tailed) } & \multirow{2}{*}{$\begin{array}{c}\text { Mean } \\
\text { difference }\end{array}$} & \multicolumn{2}{c|}{$\begin{array}{c}95 \% \text { Confidence Interval } \\
\text { of the Difference }\end{array}$} \\
\cline { 6 - 8 } & & & & & Lower & Upper \\
\hline Textual gloss & 11.800 & 14 & .000 & 5.3355 & 4.695 & 6.776 \\
Control & 8.392 & 14 & .000 & 3.3022 & 2.773 & 4.631 \\
\hline
\end{tabular}

As the above table shows, the mean of the textual gloss group is 5.33 and the mean of control group is 3.3 .The differences between the means of the groups show that the participants in text gloss group performed better than those of control group in idiom learning measures. A matched t-test was run to see if the difference is significant. The second null hypothesis is rejected, since the significance level $(.000)$ is smaller than the alpha level $(0.05)$, and the difference between the means of two groups is statistically significant.

Table 4.5. One Sample t-Test Results of the Production Test: Control and Picture Gloss Groups

\begin{tabular}{|l|c|c|c|c|c|c|}
\hline & \multicolumn{9}{|c|}{ Test Value = 0} \\
\cline { 5 - 7 } & \multirow{2}{*}{$\mathrm{t}$} & \multirow{2}{*}{$\mathrm{df}$} & \multirow{2}{*}{ Sig. (2-tailed) } & \multirow{2}{*}{$\begin{array}{c}\text { Mean } \\
\text { Difference }\end{array}$} & \multicolumn{2}{c|}{$\begin{array}{c}\text { 95\% Confidence Interval of } \\
\text { the Difference }\end{array}$} \\
\cline { 5 - 7 } & & & & & Lower & Upper \\
\hline Textual gloss & 10.776 & 14 & .000 & 6.0355 & 5.133 & 7.549 \\
Control & 8.392 & 14 & .000 & 3.3022 & 2.773 & 4.631 \\
\hline
\end{tabular}

As table 4.5. indicates, the difference between the means of two group is significant. The second null hypothesis is rejected, since the observed $t$ is greater than the critical t with 14 degree of freedom at the 0.05 level of significant,. Based on the results presented in table 4.12 , the level of significance is. $000<0.05$. Thus it can be concluded that a meaningful difference between the means of picture gloss and control group in L2 idiom learning exists.

Table 4.6. One Sample t-Test Results of the Production Test: Control and Text plus Picture Gloss Groups

\begin{tabular}{|l|c|c|c|c|c|c|}
\hline \multirow{2}{*}{} & \multicolumn{9}{|c|}{ Test Value $=0$} \\
\cline { 5 - 7 } & \multirow{2}{*}{$\mathrm{t}$} & \multirow{2}{*}{ Df } & \multirow{2}{*}{ Sig. (2-tailed) } & $\begin{array}{c}\text { Mean } \\
\text { Difference }\end{array}$ & \multicolumn{2}{c|}{$\begin{array}{c}\text { 95\% Confidence Interval of } \\
\text { the Difference }\end{array}$} \\
\cline { 6 - 7 } & & & & & Lower & Upper \\
\hline Text-Pic & 12.430 & 14 & .000 & 8.2022 & 6.106 & 8.701 \\
Control & 8.392 & 14 & .000 & 3.3022 & 2.773 & 4.631 \\
\hline
\end{tabular}

As table4.6. elucidates, there is a difference between the means of the two groups. This difference shows that the participants in combination gloss group outperformed those of the control group in idiom learning measures. A matched ttest was run to see if the difference is significant. The second null hypothesis is rejected, since the significance level $(.000)$ is smaller than the alpha level $(0.05)$, and the difference between the means of two groups is statistically significant. Therefore, being exposed to text plus picture gloss has a significant effect on L2 readers' learning of target idioms. 


\subsection{Comparison of comprehension Test Results of Three Gloss Groups}

To confirm or reject the third null hypothesis (i.e., none of the gloss types, text, picture, text plus picture, have a more significant effect on L2 readers' comprehension of an online computerized reading text, as measured by a comprehension test.), first, the descriptive statistics of the participants' performance on the means and standard deviations of three gloss groups of reading comprehension test were computed. Second, One-way ANOVA was used to calculate the amount of variance between and within the gloss groups (text, picture, text plus picture). Third, Post hoc Scheffe test was run to determine whether the difference existing among group was significantly meaningful for text gloss, picture gloss, and mix gloss.

Table 4.7. Descriptive Statistics: Performance of the gloss groups on Reading Comprehension Test

\begin{tabular}{|l|c|c|c|c|c|}
\hline \multicolumn{1}{|c|}{ Group } & $\mathrm{N}$ & Mean & Std. Deviation & minimum & maximum \\
\hline Text gloss & 15 & 5.867 & 2.1186 & 2.5 & 8.0 \\
Picture gloss & 15 & 5.900 & 1.8541 & 3.5 & 9.5 \\
Mix gloss & 15 & 6.000 & 1.8994 & 3.5 & 9.0 \\
\hline
\end{tabular}

Table 4.7. represents that the standard deviation score of the participants are $2.11,1.85$, and 1.89 respectively and the mean of the three gloss groups, text, picture, and mix are 5.86, 5.9, and 6.0 respectively.. The minimum scores of the participants on reading comprehension test are $2.5,3.5,3.5$, and the maximum scores are 8.0, 9.5, and 9.0 respectively.

Table4.7. elucidates the descriptive statistics of the three gloss groups' achieved scores on text comprehension measures and the total comparison of the scores of the participants among the three gloss groups. The difference among the means of three gloss groups on reading comprehension test showed that the pictorial gloss group outperformed the textual gloss group and also it showed the combination gloss group outperformed all other groups (textual and pictorial) on this test.

One-way ANOVA as performed in the environment of the software SPSS 13 was used in order to analyze the data. In Table 4.16, One-way ANOVA was run on comprehension scores to determine whether or not type of gloss had a significant effect on the reading comprehension.

Table 4.8. One-way ANOVA Results of the Comprehension Test for Three Gloss Groups

\begin{tabular}{|l|c|c|c|c|c|}
\hline & $\begin{array}{c}\text { Sum of } \\
\text { Squares }\end{array}$ & $\mathrm{df}$ & Mean Square & $\mathrm{F}$ & Sig. \\
\hline Between groups & .136 & 2 & .075 & & \\
Within Groups & 159.722 & 42 & 3.718 & .017 & .978 \\
Total & 159.858 & 44 & & & \\
\hline
\end{tabular}

According to Table 4.8., the third null hypothesis is confirmed, since the significant level (.981) is greater than the alpha level (0.05), it can be concluded that there are no significant differences among the three gloss groups (text, picture, and mix). The results of this study suggest that exposure to types of gloss in this study did not appear to have a differential effect on the learners' abilities to comprehend $\mathrm{L} 2$ texts.

The Post hoc Scheffe test was administered to show if differences existing among gloss groups were significantly meaningful in comprehension L2 texts. The results of the post hoc test have been indicated in Table 4.9.

Table 4.9. Post hoc Scheffe Results of the Comprehension Test for Three Gloss Groups

Multiple Comparisons

\begin{tabular}{|l|c|c|c|c|c|}
\hline \multirow{2}{*}{ (I)group2 (J) group2 } & \multirow{2}{*}{$\begin{array}{c}\text { Mean } \\
\text { Difference (I-J) }\end{array}$} & \multirow{2}{*}{ Std.Error } & \multirow{2}{*}{ Sig. } & \multicolumn{2}{|c|}{ 95\% Confidence Interval } \\
\cline { 5 - 6 } & -.03333 & .72445 & .996 & -1.7713 & 1.7122 \\
\hline Text picture & -.13333 & .72445 & .980 & -1.9193 & 1.6154 \\
mix & .03333 & .72445 & .996 & -1.7122 & 1.7713 \\
\hline Picture text & -.10000 & .72445 & .981 & -1.8484 & 1.6484 \\
mix & .13333 & .72445 & .980 & -1.6154 & 1.9193 \\
\hline mix text & .10000 & .721445 & .981 & -1.6484 & 1.8484 \\
picture & \multicolumn{4}{|c}{} \\
\hline
\end{tabular}


The level of significant for text gloss group and picture gloss group is .996>.05. It means that there is no significant difference between these two gloss groups in reading comprehension test. The level of significance for text gloss group and mix gloss group is .980>.05. This means that no meaningful difference exists in the performance of the groups on text comprehension measures. Based on the results of the Post hoc test, the level of significance for picture gloss group and mix gloss group is .981>.05. Thus, it can be concluded that no significant difference exists between these two groups and also the results indicate that there is no meaningful differences among the three gloss types (text, picture, mix) for the reading comprehension test.

\subsection{Comparison of Production Test Results of Three Gloss Groups}

In order to support or reject the fourth null hypothesis (i.e., none of gloss types, text, picture, text plus picture, have a more significant effect on L2 readers' learning of online computerized target idioms as measured through a production test). First, the participants' performance of three gloss groups of production test through the descriptive statistics were calculated. Then, one-way ANOVA was administered for the achieved experimental data to determine whether or not the difference among the three gloss groups regarding producing target idioms was significant. Finally, Analysis of variance procedure was followed by Post hoc Scheffe test. This test was run to show level of significant differences among groups.

Table 4.10. Descriptive Statistics: Performance of the Gloss Group on Production Test

\begin{tabular}{|l|c|c|c|c|c|}
\hline \multicolumn{1}{|c|}{ Group } & $\mathrm{N}$ & Mean & Std. Deviation & Minimum & maximum \\
\hline Text gloss & 15 & 5.335 & 1.7986 & 2.5 & 9.0 \\
Picture gloss & 15 & 6.035 & 2.2713 & 3.0 & 10.5 \\
Mix gloss & 15 & 8.202 & 1.4455 & 6.0 & 10.5 \\
\hline
\end{tabular}

Table 4.10. elucidates the descriptive statistics of the three gloss groups' scores on the production test and the total comparison of the scores of the participants among the three gloss groups. The minimum scores of participants on the production test are 2.5, 3.0, 6.0 and the maximum scores are 9.0, 10.5, and 10.5 respectively. According to Table 4.18, the mean of the three gloss groups, text, picture, text plus picture, are $5.35,6.0$, and 8.2 respectively. The standard deviation scores of participants are $1.79,2.27$, and 1.44 respectively. The difference between the means of the three gloss groups, text, picture, text plus picture, on production test show that the pictorial gloss group outperform the textual gloss group and the combination gloss group outperform the other groups (textual and pictorial) on the production test. In Table 4.11. one- way ANOVA was computed on the production scores to determine whether the type of gloss had a significant effect on idiom learning.

Table 4.11. one-way ANOVA results of the Production Test for Three Gloss Groups

\begin{tabular}{|c|c|c|c|c|c|}
\hline \multicolumn{6}{|c|}{ ANOVA } \\
\hline & $\begin{array}{c}\text { Sum of } \\
\text { Squares }\end{array}$ & $d f$ & Mean Square & $\mathrm{F}$ & Sig. \\
\hline Between groups & 66.977 & 2 & 33.459 & & \\
\hline Within Groups & 158.989 & 42 & 3.654 & 8.658 & .001 \\
\hline Total & 225.966 & 44 & & & \\
\hline
\end{tabular}

Based on the results obtained from ANOVA test in Table 11, significant difference among participants' production measures in three gloss groups confirmed. In other words, therefore, the forth null hypothesis is rejected, since the significant level (.0.01) is smaller than the alpha level $(0.05)$ and there are significant differences among the three gloss groups.

ANOVA procedure was followed by Post hoc Scheffe test. This test was run to reveal the level of significant differences among the three gloss groups. The details of this post hoc test are presented in the following Table.

Table 4.12. Post hoc Scheffe Results of the Production Test for Three Gloss Groups 


\begin{tabular}{|l|c|c|c|c|c|}
\hline \multirow{2}{*}{ (I)group2 (J) group2 } & \multirow{2}{*}{$\begin{array}{c}\text { Mean } \\
\text { Difference (I-J) }\end{array}$} & \multirow{2}{*}{ Std.Error } & \multirow{2}{*}{ Sig. } & \multicolumn{2}{|c|}{ 95\% Confidence Interval } \\
\cline { 5 - 6 } & -.70000 & .71221 & .589 & -2.4321 & 1.0265 \\
\hline Text picture & $-2.86655^{\star}$ & .71221 & .001 & -4.6103 & -1.1497 \\
mix & .70000 & .71221 & .589 & -1.0265 & 2.4321 \\
\hline picture text & $-2.16655^{\star}$ & .71221 & .012 & -3.8777 & -.4259 \\
mix & 2.86655 & .71221 & .001 & 1.1497 & 4.6103 \\
\hline mix text & $2.16655^{\star}$ & .71221 & .012 & .4259 & 3.8777 \\
picture & &
\end{tabular}

*. The mean difference is significant at the .05 level.

The level of significance for text gloss group and picture gloss group is .589> .05, this shows that no significant difference between these two glossing conditions exists in production test. The level of significance for text gloss group and mix gloss group is $.001<.05$. It means that there is a meaningful difference in the performance of the groups in idiom gains. Based on Table 4.12, the level of significance for picture gloss group and mix gloss group is .012<.05 meaning that there is a significant difference between these two groups in producing target words.

The results obtained from the Post hoc Scheffe test presented in Table 4.12. show that the mix gloss group significantly outperformed all other groups on the production measures.

Considering the first research question, the results of the present study indicate that the participants exposed to multimedia glosses (textual, pictorial, textual plus pictorial) outperformed those who received no such instruction, and there was a significant difference in the performance of gloss groups and that of control group on the comprehension test. As far as reading comprehension is concerned, the three gloss groups significantly outperformed the control group even though no significant difference among experimental groups was detected. These findings are not surprising and are in tune with the previous findings that have shown reading comprehension to be affected by the inclusion of annotations. Glosses whether multimedia or traditional have had significant effect on the comprehension of a written text (Davis, 1989; Jacobs, DuFon, \& Hong, 1994; Lomicka, 1998; Bowles, 2004; Mayer, 2005).

According to Davis (1989) providing glosses when reading the text helped students recall significantly more of the reading passage than those with no glass. In addition, Lomicka (1998) concluded that multimedia annotations seemed to have a positive effect on the comprehension of a written text. She argued that her results were not significant due to the small number of the participants and that future research was needed to further investigate these issues.

This finding of the study supports the study conducted by Bowles (2004), who employed think- a loud protocols and compared computerized glosses with the traditional ones in text comprehension measures. The results indicated that both experimental groups, multimedia and traditional gloss groups, had an advantage over the control group in reading comprehension. Along the same lines, in the present study, all groups exposed to glosses outperformed the control group and there was a meaningful difference between the performance of the participants in the gloss groups and those of the control group in comprehension of an online computerized passage.

Considering the second research question, which investigated the effect of types of gloss on production tasks, all groups exposed to glosses outperformed the control group in producing target idiom. Also a significant difference between the three gloss groups and the control group was found in the production task. These results contradict with the finding of the previous studies that have shown production of target idiom items not to be affected by the inclusion of annotations (Chun \& Plass, 1996; Lomicka, 1998; Kost et al., 1999; Bowles, 2004).

Idiom learning is higher when L2 readers have access to glosses. It can be concluded that providing different types of glosses is effective in the learning of target idioms. Along the same lines, the present study indicated that all multimedia gloss groups outperformed the control group and a meaningful difference existed between gloss groups and control group in producing target idioms.

In response to the third research question in which the effect of any types of glosses is investigated related to the computerized text comprehension, the picture gloss group outperformed the text gloss group and the combination gloss group outperformed all the other. In other words, comprehension of the text was better aided by visual and textual information as provided by combination glosses.

As proposed by Mayer $(2001,2005)$ providing learners with both picture and text glosses so that they could process information through different channels allowed participants to better comprehend the text. Participants in the text only gloss group and picture only gloss group, but they did not significantly outperform each other. That is, there was no meaningful difference among gloss groups in reading comprehension. It seemed that any type of gloss (text, picture, text plus picture) in comparison with each other did not offer enough support to overall comprehension of the passage.

Finally, concerning the fourth research question in which the effect of type of gloss on the production task was 
investigated, the picture gloss group insignificantly outperformed the text gloss group but the combination gloss group significantly outperformed all the others. In other words, a meaningful difference existed in the production of target idioms.

The results of this study suggested that a combination of textual and pictorial glosses was more beneficial to the learners in vocabulary learning, possibly due to the fact that they received two modes of input (Ellis, 1994), namely verbal and visual.

The outcome of this research that text plus picture group significantly outperformed the text only and picture only gloss groups in producing target idioms, is interesting and clearly contrasts with the results of the third research question, in which no meaningful difference among any gloss groups (text, picture, text plus picture) in reading comprehension test was found. This seems to indicate that multimedia glosses had a different effect on reading comprehension and idiom learning. As it is mentioned above, it seems that the three gloss types in comparison with each other do not offer enough support to overall understanding of the passage, but significantly aid in learning target idiom items.

In the mix gloss group, where students got a text gloss along with the picture, they did not have to interpret what the picture meant and most of them read aloud the definition given. In other words, most participants took advantage of combination gloss group. The appearance of both text and picture seemed to have a cognitive impact on the participants' idiom learning and reading comprehension. However, it eventually only had a significant effect on idiom learning, as shown by the quantitative results of the present study.

These cases would help explaining differences between the mix gloss group and the picture gloss group, since it seemed that being able to access some pictures was not very helpful for the participants. Some pictures were less explicit than definition and somehow open to interpretation, and some of the participants found it harder to get a suitable meaning for the picture accessed in the gloss. Nevertheless, if we accepted this interpretation of the results, we would still need to explain why participants in the mix gloss group significantly outscored the participants in the text gloss group.

Therefore, the findings related to the fourth research question seemed reasonable that reading the production of target idioms, picture gloss group insignificantly outperformed text gloss group. But, mix gloss group significantly outperformed text only and picture only gloss groups in idiom learning. This finding indicates that the pictures of the words were more beneficial for learning of target idiom than their definitions, but pictures only are not as comprehensible as combination of pictures and definitions since as mentioned above, some pictures are less explicit than definitions and somehow open to interpretation. These final results are consistent whit the findings of several studies that have found combination glosses more beneficial for incidental vocabulary learning(Al-Seghayer, 2001 ; Kost et al., 1999; Plass et al., 1998).

\section{Conclusion}

The findings of the present study demonstrate first that all multimedia gloss groups comprehend online computerized L2 texts significantly better than the control group. Second, Multimedia gloss groups learn the target idioms better than the control group in the production of the target idiom items. Third, regarding reading comprehension, the combination gloss group insignificantly comprehends an online computerized L2 text better than all other gloss groups. Finally, regarding idiom learning, the combination gloss group significantly outperforms the other two gloss groups.

The results of this study also reflect the fact that utilizing computers and multimedia glosses can be influential in language teaching un general, and online computerized L2 text comprehension as well as idiom learning in particular.

To conclude, unlike traditional idiom teaching in which learners are exposed to scarce authentic learning material as well as monotonous idiom learning method, the integration of CALL to idiom learning and reading comprehension can become a dynamic learning process in which ample learning materials from multiple sources, both textual and pictorial, are adopted, and varied learning modes which combines classroom learning with online learning are realized.

\section{References}

Adams, M.J. (1990). Beginning to read: Thinking and Learning about print. Cambridge: MA: MIT Press.

Aisenstadt, E. (1979). Collocability restrictions in dictionaries. ITL: Review of Applied Linguistics, 45(6), 71-74.

Alexander, R.J. (1987). Problems in understanding and teaching idiomaticity in English. Anglistik und Englischunterricht, 32, $105-122$.

Al-Seghayer, K. (2001). The effect of multimedia annotation modes on L2 vocabulary acquisition: A comparative study. Language Learning \&Technology, 5(1), 202-232. Retrieved February 7, 2013, from: http://lt.msu.edu/vol5num1/alseghayer/default.html.

Boers, F. (1992). Raising metaphoric awareness The Internet TESL Journal, Retrieved,November 25, 2012, from http://nadabs.tripod.com 
Bowles, M. A. (2004). L2 glossing: To CALL or not to CALL. Hispania, 87(3), 541-552.

Chafe, W.L. (1968). Idiomaticity as an anomaly in the Chomskyan paradigm. Foundations of Language, 4, 109-127.

Chastain, K. (1988). Developing second language skills. Theory and practice. Engewood cliffx, NJ: Harcourt Brace Jovanovich, publishers.

Cooper, T.C. (1998), Teaching Idioms. Foreign Language Annuals. 31,3,266-335.

Cooper, T.C. (1999). Processing of idioms by L2 learners of English. TESOL Quarterly, 33, 233-62.

Cowie, A. P. (1998). Phraseological dictionaries: Some East-West comparisons. In A.P. Cowie (Ed), Phraseology, Theory, Analysis, and Applications (PP.209-228). Oxford: Clarendon Press.

Cronk, B. \& Schweigert, W. (1992). The comprehension of idioms. The effects of familiarity, literalness and usage. Applied Psycholinguistics, 13,3, 131-146.

Cruse, D. (1986). Lexical Semantics. Cambridge: Cambridge University Press.

Davis, J. N. (1989). Facilitating effects of marginal glosses on foreign language reading. The Modern Language Journal, 73(1), 41-48.

De Ridder, I. (2002). Visible or invisible links: Does the highlighting of hyperlinks affect incidental vocabulary learning, text comprehension, and the reading process? Language Learning \& Technology, 6(1), 123-46.

Dixon, R. J. (1994). Essential Idioms in English. New Jersey: Prentice Hall Regents.

Drew, P., \& Holt, E. (1988). Complainable matters: the use of idiomatic expression in Ellis, R. (1994). The study of second language acquisition. Oxford: Oxford University Press.

Eskey, D. E. (2002). Reading and the teaching of L2 reading. TESOLJournal, 11(1), 5-9.

Fazly, A. \& Cook, P. \& Stevenson, S. (2009). Unsupervised Type and Token Identification of Idiomatic Expression. Computational Linguistic 35,1, 61-103.

Fillmore, C., Kay, P., \& O'Connor, M. (1988). Regularity and idiomaticity in grammatical constructions: The case of Let alone. Language, 64, 501-538.

Fraser, B. (1970). Idioms within a transformational grammar. Foundations of Language, 6(1), 22-42.

Gibbs, R.W. (1980). Spilling the beans on understanding and memory for idioms in conversation. Memory and cognition 8, 449-456.

Gibbs, R. W. (1986). Skating on thin ice: Literal mening and understanding in Gibbs, R. W., \& Nayak, N. (1989). Psycholinguistic studies on the syntactic behavior of idioms. Cognitive Psychology, 21, 100- 138.

Glucksberg, S. (2001). On the fates of literal meanings. Paper presented at Workshop Towards an Experimental Progmatics, Lyons, France.

Harless, W., Zier, A., \& Duncan, R. (1999) Virtual dialogs with native speakers: The evaluation of an interactive multimedia method. CALICO Journal 16(3), 313-336.

Hauptman, P. (2000). Nature of difficulty and ease in second language reading. Foreign Language Annals, 33, 622-631.

Howarth, P. (1998). Phraseology and second language proficiency. Applied Linguistics, 19(1), 24-44.

Huckin, T., \& Bloch, J. (1993). Strategies for inferring word-meaning in context: A cognitive model.T. Huckin, M. Haynes \& J. Coady, (Eds.), Second Language reading andvocabulary learning (pp. 153-1796). Norwood, NJ: Ablex Publishing Corporation.

Hudson, r. A (1980). Sociolinguistics. Cambridge: Cambridge University Press.

Hulstijn, J. H. (1992). Retention of inferred and given word meanings: Experiments in incidental vocabulary learning. In P. J. L. Arnaud \& H. Béjoint (Eds.). Vocabulary and applied linguistics. (pp. 113-125). London: Macmilla.

Irujo, S. (1986). "A Piece of Cake: Learning and teaching idioms." ELT Journal 40,3,236-242.

Jackendoff R. (1997). Twisting the night away. Language, 73,3 534-559.

Jacobs, G. M., Du Fon, P., \& Hong, F. C. (1994). L1 and L2 vocabulary glosses in L2 reading passages: Their effectiveness for increasing comprehension and vocabulary knowledge. Journal of Research in Reading, 17(1), 19-28.

Katz, J., \& Postal, P. (1963). Semantic interpretation of idioms and sentences containing them. MI Research Laboratory O Electronics, Quarterly Progress Report, 70, 275-282.

Knight, S. (1994). Dictionary use while reading: The effects on comprehension and vocabulary acquisition for students of different verbal abilities. Modern language Journal, 78 (3), 285-299.

Koren, S. (1999). Vocabulary instruction through hypertext. Are there advantages over conventional methods of teaching? Retrieved May 5, 2013, from Web:http://Korens.mail.biu.ac.il.

Kovecses, Z., \& Szabo, P. (1996). Idioms: a view from cognitive semantics. Applied Linguistics, 17(3), 326-355.

Lakoff, G. (1987). Women, fire and dangerous things: what categories reveal about the mind. Chicago: Chicago University Press.

Landry, K. L. (2002). Schemata in Second Language Reading. The Reading Matrix, 2(3), 75-91.

Levenston, E. A. (1979). Second language acquisition: Issues and problems. Interlanguage studies Bulletin, 4, 147-160.

Levorato, M. C., \& Cacciari, C. (1995). The effects of different tasks on the word comprehension and production of idioms in children. Journal of Experiment Psychology. 60, 261-283.

Liontas, J.I. (2001). That's all Greek to me! The comprehension of modern Greek phrasal idioms. The reading Matrix: An introduction Online Journal, 1/1, 1-32. Retrieved April, 12 2013, from www.readingmatrix.com/articles.john_liontas/article.pdf.

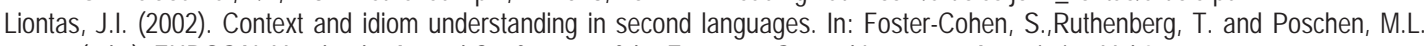
(eds.), EUROSAL Yearbook: Annual Conference of the European Second Language Association. Vol.2.

Proceedings of the 2002 Annual Conference of the European Second Language Association. Amesterdam/Philadelphia: John Benjamin Publishing Company, pp. 155-185.

Makkai, A. (1972). Idiom Structure in English. The Hague: Mouton. 
Makoto,Y. (2006). L1 and L2 glosses: Their effects on incidental vocabulary learning. Language Learning \& Technology, 10(3), $14-21$.

Malkiel, Y. (1959). Studies in irreversible binomails. Lingua, 8, 113-160.

Mayer, R. E. (2001). Multimedia learning. New York: Cambridge University Press.

Mayer, R. E. (2005). Cognitive theory of multimedia learning. In Mayer, R.E. (Ed.), The Cambridge handbook of multimedia learning (pp. 31-48). New York: Cambridge University Press.

McCarthy, M.J. (1998). Spoken language and applied linguistics. Cambridge: Cambridge University Press.

Minkskoff, E. H. (1982). Sharpening language skills in secondary LD students. Academic Therapy, 18, 53-60.

Moon, R. (1992). "Textual aspects of fixed expressions in learner's dictionaries". In Ahmaud, P. J. L. \& Bejoints, H. (Eds.), Vocabulary and Applied Linguistics, Basingstoke, Macmillan. 4-27.

Nagata, N. (1999). The effectiveness of computer-assisted interactive glosses. Foreign Language Annals, 32(4), 469-479.

Nelson, T. (2001). Practice Test II. Hong Kong: Bright Sun Printing Press.

Newmeyer, F. J. (1974). The regularity of idiom behavior. Lingua, 34, 327-342.

Numberg, G., Sag, L., \& Wasow, T. (1994). Idioms. Language, 70, 491-534.

Paivio, A. (1986). Mental representation: A dual-coding approach. New York: Oxford University Press.

Pawley, A., \& Syder, F.H. (1983). Two puzzles for linguistic theory: native like selection and native like fluency. In J. C. Richards \& R. W. Schmidt (Eds.), Language and communication (pp. 191-225).

Roby, W. B. (1999). What's in a gloss? Language Learning and Technology, 2(2), 94-101. Retrieved May 14, 2013, from http://llt.msu.edu/vol2 num2/roby/index.html.

Rott, S., \& Williams, J. (2003). Making form-meaning connections while reading: A Qualitative analysis of word processing. Reading in a Foreign Language, 15(1), 52-74. Retrieved February 15, 2013, from http://nflrc.hawaii.edu/rfl/April2003/rott/rott.

Sadeghi, A. R. (2005). Esp in Iran: A transition from present state. In: G. R. Kiany, \& M. Khayyamdar, (Eds.), Processdings of the First National ESP/EAP Conference, 2, Tehran.

Schmidt, R. (1990). The role of consciousness in second language learning. Applied Linguistics, 11,129-158.

Simpson, R. \& Mendis, D.(2003). A corpus-based study of idioms in academic speech. TESOL Quarterly, 37 (Fall) 419-441.

Sullivan, A. (2007). Pocket English Idioms. London: Oxford University Press.

Weinreich, U. (1969). Problems in the analysis of idioms. In J. Puhvel (Eds.), Substance and Structure of language (pp. 23-81). Berkeley \& Los Angeles: University of California Press.

Widdowson, H. G. (1983). Learning purpose and language use. London: Oxford University Press.

Wood, M. M. (1981). A Definition of idiom. Unpublished Master of Arts, University of Birmingham, Birmingham.

Yeh, Y., \& Wang, C. W. (2003). Effects of multimedia vocabulary annotations and learning styles on vocabulary learning. CALICO Journal, 21(1), 131-144.

Yoshii, M. \& Flaitz, J. (2002). Second Language Incidental Vocabulary Retention: The Effect of Picture and Annotation Types. CALICO Journal, 20(1), 33-58. 